\title{
ANÁLISE DO TRABALHO PSICOPEDAGÓGICO EM UMA INSTITUIÇÃO DE ENSINO PÚBLICO DE RIO VERDE GOIÁS
}

\section{ARTIGO ORIGINAL}

SARAIVA, Maria Cristina Campos ${ }^{1}$, MARTINS, Vanéria Sousa²

SARAIVA, Maria Cristina Campos. MARTINS, Vanéria Sousa. Análise do trabalho psicopedagógico em uma instituição de ensino público de Rio Verde Goiás. Revista Científica Multidisciplinar Núcleo do Conhecimento. Ano. 06, Ed. 10, Vol. 01, pp. 136-151. Outubro 2021. ISSN: 2448-0959, Link de acesso: https://www.nucleodoconhecimento.com.br/educacao/trabalho-psicopedagogico, DOI: 10.32749/nucleodoconhecimento.com.br/educacao/trabalho-psicopedagogico

\section{RESUMO}

As diversas discussões sobre inclusão e acessibilidade permitiram que crianças, adolescentes, jovens e adultos pudessem ter o direito de frequentar uma escola com qualidade. $\mathrm{O}$ presente estudo justificou-se na desafiadora prática existente para a permanência do aluno que necessita de atendimento educacional especial na escola e teve como objetivos analisar as práticas pedagógicas desenvolvidas no AEE (atendimento educacional especializado) e pelos professores regentes para os alunos com necessidades educacionais especiais e conhecer as necessidades e as potencialidades dos alunos. Tendo como questão norteadora desse trabalho: Quais as principais práticas pedagógicas desenvolvidas pelos professores da educação especial para um bom resultado na tarefa desenvolvida? O estudo caracterizou-se pela metodologia de pesquisa de campo, que envolveu uma amostra com 22 alunos de uma escola pública de Rio Verde, com necessidades educacionais especiais com

\footnotetext{
1 Pós-graduação em Docência do Ensino Superior, Gestão Escolar e Coordenação Pedagógica, Neuropsicopedagogia e Educação Inclusiva, Atendimento Educacional especializado, Psicomotricidade, Educação de Jovens e Adultos, Psicopedagogia Institucional e Clínica, Graduação em Pedagogia Licenciatura em Filosofia. 6313276081091722.

${ }^{2}$ Orientadora. 3641140130322008.
}

RC: 98389

Disponível em: https://www.nucleodoconhecimento.com.br/educacao/trabalhopsicopedagogico 
idade entre 11 e 22 anos. A pesquisa foi realizada durante o terceiro bimestre do ano letivo de 2018 com duração de 8 semanas. Dessa forma, conclui-se que são necessários novos estudos que investiguem as causas das dificuldades de aprendizagem dos alunos com a utilização de diferentes práticas metodológicas.

Palavras-chave: aprendizagem, educação, inclusão.

\section{INTRODUÇÃO}

A educação especial inclusiva não se refere somente a tornar as escolas acessíveis, mas sim, de "tornar-se proativo na indicação de barreiras e obstáculos que os estudantes encontram na tentativa de acesso a oportunidades de educação de qualidade, bem como na eliminação das barreiras e obstáculos que levam à exclusão" (UNESCO, s.d.). O aumento das discussões sobre inclusão e acessibilidade, possibilitaram que milhões de pessoas tivessem o direito de frequentar uma escola com qualidade.

De acordo com Penteado e Guzzo (2010), a educação representa uma experiência pessoal, social e política ampla e abrangente, tendo em vista sua finalidade e implicação para a qualidade de vida e para a cidadania.

Desenvolvimento, segundo o dicionário online do site Google, significa a "ação ou efeito de desenvolver(-se)", também pode ser sinônimo de "crescimento, progresso, adiantamento", de formas a abranger "crescimento econômico, social e político de um país, região, comunidade etc.", "aumento dos atributos físicos; crescimento", "aumento das qualidades morais, psicológicas, intelectuais etc.".

Aprender é um potencial do ser humano e está inserido no cotidiano dos indivíduos desde o momento em que nascem. Ensinar, propicia o desenvolvimento intelectual, psicológico e moralmente, "fornecendo aos aprendizes situações planejadas, de modo que possam viver as experiências necessárias para produzir neles as modificações desejadas de uma maneira, mais ou menos estável, porém crescente" (ASBAHR 2011).

RC: 98389

Disponível em: https://www.nucleodoconhecimento.com.br/educacao/trabalhopsicopedagogico 
Segundo Leão et al (2006) a inclusão da criança com um grau acentuado de dificuldade nas classes comuns é marcada por contínuas queixas dos professores no que se refere às práticas pedagógicas que atinjam o aprendizado do aluno de forma satisfatória. Efetivam-se aí práticas educativas que possibilita que crianças, adolescentes e jovens em idade escolar tenham garantidos o direito de não somente frequentar uma escola, mas aprender.

Para Vygotsky (1991), a aprendizagem é uma experiência social, a qual é mediada pela interação entre a linguagem e a ação.

O acesso e a permanência da criança na escola são um direito constitucional garantido para todos, e um dever das instâncias governamentais. Portanto a Constituição Federal de 1988 tem como um dos objetivos fundamentais

promover o bem de todos, sem preconceitos de origem, raça, sexo, cor, idade e quaisquer outras formas de discriminação" (art. $3^{\circ}$ inciso IV). Define, no artigo 205, a educação como um direito de todos, garantindo o pleno desenvolvimento da pessoa, o exercício da cidadania e a qualificação para o trabalho. No seu artigo 206, inciso I, estabelece a "igualdade de condições de acesso e permanência na escola", como um dos princípios para o ensino e, garante como dever do Estado, a oferta do atendimento educacional especializado, preferencialmente na rede regular de ensino (BRASIL, 1988).

$\mathrm{Na}$ educação inclusiva é importante que o professor ressignifique sua compreensão sobre o que são conteúdos curriculares, que os autores apresentam a seguir

diversifiquei minhas aulas, utilizando muito o lúdico, trabalhando em pequenos grupos, pois penso que o professor deve fazer do espaço da sala de aula, um ambiente de socialização de aprendizagens, onde os alunos adquiram normas e valores, condutas de respeito, responsabilidade, solidariedade, cooperação, visão crítica, buscando sempre a inclusão incondicional de todos os alunos na escola regular. (PIVETA; RODRIGUES; NOGUEIRA, 2005, p 141).

No que se refere aos materiais curriculares Meserlian (2009, p. 136) afirma que um aspecto relevante nas aulas, é utilizar os recursos visuais, que auxiliam na memorização gráfica das palavras ou dos textos, que terão significado somente se forem contextualizadas, dessa forma, os objetivos das aulas podem ser atingidos com mais eficiência.

RC: 98389

Disponível em: https://www.nucleodoconhecimento.com.br/educacao/trabalhopsicopedagogico 
O estudo justificou-se na importância da intervenção neuro psicopedagógica no ambiente escolar para crianças com dificuldades no desenvolvimento da aprendizagem e na complexidade e desafiadora prática existente para a continuação do aluno que necessita de atendimento educacional especial na escola.

A neuropsicopedagogia é conhecida como a relação entre os estudos das neurociências com os conhecimentos da psicologia cognitiva e da pedagogia, ou seja, é uma ciência interdisciplinar que estuda as relações entre o funcionamento do sistema nervoso e a aprendizagem humana (BORGES, 2018).

A neuropsicopedagogia é uma área de estudo das neurociências, que tem como objetivo analisar os processos cognitivos, as potencialidades pessoais e perfil socioeconômico, com o intuito de construir indicadores formais para a intervenção clínica de alunos com baixo desempenho ou que apresentam disfunções neurais (ROTTA apud CONSENZA, 2011, p. 50).

Portanto, a questão norteadora desse trabalho é: Quais as principais práticas pedagógicas desenvolvidas pelos professores da educação especial para um bom resultado na tarefa desenvolvida?

O presente estudo teve como objetivos analisar as práticas pedagógicas desenvolvidas no AEE (atendimento educacional especializado) para os alunos com necessidades educacionais especiais e conhecer as maiores dificuldades desses alunos.

\section{METODOLOGIA}

O presente estudo foi uma pesquisa de campo e envolveu uma amostra com 22 alunos de uma escola pública do estado na cidade de Rio Verde, Goiás. A escola pesquisada contém um número significativo de crianças com necessidades educacionais especiais com idade entre 11 e 22 anos.

RC: 98389

Disponível em: https://www.nucleodoconhecimento.com.br/educacao/trabalhopsicopedagogico 
Nesta escola, os alunos são acompanhados diariamente em sala de aula pelos professores de apoio, todos os projetos e atividades desenvolvidas tem sua parcela de participação de alunos especiais, mostrando assim que mesmo com suas limitações estes podem apresentar seus trabalhos e avanços na aprendizagem.

A pesquisa foi realizada durante o primeiro bimestre do ano letivo de $2018 \mathrm{com}$ duração de 8 semanas.

A escola possui uma sala de $\mathrm{AEE}$, onde os alunos são atendidos diariamente pela psicopedagoga da escola. Portanto, em cada dia de acompanhamento com os alunos do AEE, tivemos a oportunidade de conhecer o histórico familiar e a deficiência de cada um, no objetivo de concluir a pesquisa fazendo uma investigação sólida do contexto social a que os alunos estão inseridos.

Após o diagnóstico cedido pela psicopedagoga da escola informando as limitações e potencialidades dos alunos com necessidades educacionais especiais as pesquisadoras se integraram sobre processo ensino aprendizagem para esses educandos. Foram realizadas observações diárias e sistematizada/registrada em relatório descritivo elencando as participações dos educandos nas atividades, a apropriação e construção de conceitos relativos aos conteúdos.

Participaram como mediadores do processo ensino aprendizagem as pesquisadoras deste estudo, a psicopedagoga através da utilização de recursos didáticos tais como: jogos pedagógicos, aulas com recursos multimídias, tecnologia assistiva e atividades lúdicas, enfim, fazendo uso de estratégias diversificadas para aprimorar as competências das linguagens de escrita, leitura, raciocínio lógico e interpretação que são essenciais para o desenvolvimento do processo de ensino aprendizagem no contexto de uma sala de ensino regular.

As observações foram realizadas na sala de recursos multifuncionais da Unidade escolar, cada aluno foi atendido individualmente e aos pares com todos os recursos disponíveis: livros, material escolar, computadores, impressora, jogos educativos, data show e jogos pedagógicos construído em minicursos.

RC: 98389

Disponível em: https://www.nucleodoconhecimento.com.br/educacao/trabalhopsicopedagogico 


\section{INCLUSÃO ESCOLAR}

De acordo com Mantoan (2003) "inclusão é sair das escolas dos diferentes e promover a escola das diferenças". Para a autora, na escola inclusiva professores e alunos aprendem uma lição que a vida dificilmente ensina, a de respeitar as diferenças. Esse é o primeiro passo para construir uma sociedade com equidade.

A ideia da escola inclusiva se fundamenta em uma filosofia que reconhece e valoriza a diversidade, como característica inerente de qualquer sociedade. Diante disso, e com base nos Direitos Humanos, sinaliza-se a necessidade de se garantir o acesso e a participação de todos, a todas as oportunidades, independentemente das particularidades de cada indivíduo.

Para Kunc (1992), a ideia principal da educação inclusiva é a valorização da diversidade e da comunidade humana. Nesse sentido, quando a educação inclusiva é recebida e desenvolvida no meio escolar, se abandona a ideia de que as crianças devem se tornar normais para contribuir para o mundo.

Para Mantoan et al (2006) a inclusão escolar significa que todas as pessoas podem ter acesso ao sistema de ensino, de forma justa. Sem tolerância para discriminações, seja de gênero, etnia, religião, classe social, condições físicas e psicológicas etc. Atualmente, o principal foco da inclusão escolar são as crianças e adolescentes portadores de necessidades educacionais especiais (NEE), esses, apresentam algum tipo de deficiência física ou psicológica. A inclusão escolar prevê então, a integração de alunos com necessidades educacionais especiais na sala de aula regular, tendo, dessa forma, as mesmas experiências e aprendizados com os estudantes que não apresentam NEE.

A Educação Especial é definida, pela lei de diretrizes e bases da educação nacional no 9.394/96, como uma modalidade de educação escolar que permeia todas as etapas e níveis de ensino. Tal lei "permite tomar a educação especial como um recurso que beneficia a todos os educandos e que atravessa o trabalho do professor 
com toda a diversidade que constitui o seu grupo de alunos" (BRASIL, 2005). Assim, se faz necessário propor alternativas inclusivas para a educação e não apenas para a escola.

Piaget citado por Streck (1994, p. 96) destaca que o "principal objetivo da educação é criar pessoas capazes de fazer coisas novas e não simplesmente repetir o que outras gerações fizeram". Partindo destas afirmações, a definição de escola inclusiva fornece uma consciência da oportunidade do acesso ao ensino, agenciando a todos os alunos as mesmas chances, em condições igualitárias nos processos de ensino-aprendizagem.

\section{SALA DE RECURSOS MULTIFUNCIONAIS}

Para contemplar o ensino aos estudantes com NEE, a escola possui uma sala de recursos multifuncionais, programa destinado às escolas das redes estadual e municipal de educação. A sala de recursos multifuncionais é equipada com materiais pedagógicos e de acessibilidade, para a realização do Atendimento Educacional Especializado (AEE), complementar ou suplementar à escolarização. A intenção é atender com qualidade alunos com deficiência, transtornos globais do desenvolvimento e altas habilidades/superdotação ou que possuem dificuldades acentuadas de aprendizagem que estejam matriculados nas classes comuns do ensino regular (GARCIA, 2013, p. 103).

\section{ATENDIMENTO EDUCACIONAL ESPECIALIZADO (AEE)}

Segundo Oliveira (1999) está previsto na Constituição de 1988 o Atendimento Educacional Especializado aos portadores de deficiência e todas as suas formas de intervenção.

No Artigo 208, da Constituição federal, fica estabelecido que o AEE ocorra na rede regular de ensino. Segundo o ministério da educação 
a) esse atendimento refere-se ao que é necessariamente diferente da educação em escolas comuns e que é necessário para melhor atender às

especificidades dos alunos com deficiência, complementando a educação escolar e devendo estar disponível em todos os níveis de ensino;

b) é um direito de todos os alunos com deficiência que necessitarem dessa complementação e precisa ser aceito por seus pais ou responsáveis e/ou

pelo próprio aluno;

c) o "preferencialmente" na rede regular de ensino significa que esse atendimento deve acontecer prioritariamente nas unidades escolares, sejam

elas comuns ou especiais, devidamente autorizadas e regidas pela nossa lei educacional. A Constituição admite ainda que o atendimento educacional

especializado pode ser oferecido fora da rede regular de ensino, já que é um complemento e não um substitutivo do ensino ministrado na escola comum

para todos os alunos;

d) o atendimento educacional especializado deve ser oferecido em horários distintos das aulas das escolas comuns, com outros objetivos, metas

e procedimentos educacionais.

e) as ações do atendimento educacional são definidas conforme o tipo de deficiência que se propõe a atender. Como exemplo, para os alunos com

deficiência auditiva o ensino da Língua Brasileira de Sinais - LIBRAS, de Português, como segunda língua, ou para os alunos cegos, o ensino do código

"Braille", de mobilidade e locomoção, ou o uso de recursos de informática, e outros;

f) os professores que atuam no atendimento educacional especializado, além da formação básica em Pedagogia, devem ter uma formação específica

para atuar com a deficiência a que se propõe a atender. Assim como o atendimento educacional especializado, os professores não substituem as funções do

professor responsável pela sala de aula das escolas comuns que têm alunos com deficiência incluídos (BRASIL, 2006, p. 9). 
De acordo com o PPP (Projeto Político Pedagógico) o Coordenador da Educação Especial é o responsável por assessorar e acompanhar o trabalho dos Profissionais de Apoio, tendo como foco a aprendizagem dos estudantes com necessidades especiais de acordo com a especificidade de cada um. Apresentar pautas prédefinidas e a partir destas avaliar as ações realizadas durante a semana anterior e fazer as adequações tanto do planejamento quanto das atividades, conforme a necessidade, a fim de garantir metodologias diferenciadas que propiciem vínculos sociais e afetivos dentro do grupo e da comunidade escolar.

Para Glat (2007) a proposta de uma escola na perspectiva da educação inclusiva deve colocar-se a frente do desafio de transformar a concepção de inclusão, posturas afetivas e sociais nesta escola da atualidade. Para isso se faz necessário a mudança de comportamento e rompimento de numerosas barreiras históricas, financeiras, físicas e atitudinais.

Segundo o Projeto político Pedagógico da unidade educacional pesquisada, a proposta visa garantir o que se desenvolva um trabalho na perspectiva da educação inclusiva, assegurando atendimento educacional especializado a todos os estudantes que possuem algum tipo de necessidade especial, criando metodologias diferenciadas que propiciem vínculos sociais e afetivos dentro do grupo e da comunidade escolar, facilitando sua aprendizagem em todos os contextos de suas vidas. Assim, são elencados alguns pontos primordiais que permeiam este formato entre a Educação Especial e Escola, com a finalidade de entendimento em relação à operacionalização, funções pedagógicas e organização das Atividades.

Nesta instituição o Professor de Atendimento Educacional Especializado (AEE) exerce a função de Coordenador da Educação Especial; planeja junto ao Profissional de Apoio, Professor Referência e Coordenador do Núcleo Diversificado, Elabora Plano de AEE por estudante com necessidade especial, de acordo com suas especificidades (potenciais e limitações); atende o estudante no máximo, 02 (duas) vezes por semana, individualmente ou em grupos; produz 
material para Sala de Recursos Multifuncionais; auxilia no desenvolvimento de habilidades que promovam a interação com os colegas e comunidade escolar.

Nesta unidade escolar é adotado no AEE o Campo Teórico da Psicopedagogia indicado por Jorge Visca, professor argentino que criou a EOCA (Entrevista Operativa Centrada na Aprendizagem). O processo diagnóstico inclui-se de uma série de passos em que se realiza o reconhecimento das dificuldades, o prognóstico e as indicações, cujo objetivo é de estudar as manifestações cognitivas afetivas da conduta do aluno em situação de aprendizagem. Permite ainda se obter uma visão conjugada e uma hipótese diretriz dos aspectos cognitivos e afetivos da aprendizagem, bem como os pontos de alerta que deve ser verificada para constatação ou não das hipóteses levantadas. (VISCA, 1995).

A EOCA é utilizada como o início de todo processo de investigação diagnóstica das dificuldades de aprendizagem. Ela consiste em uma entrevista estruturada, com o intuito de evidenciar a aprendizagem, dependendo da idade do educando e da queixa realizada pela família e ou comunidade escolar. Com o diagnóstico do indivíduo em mãos, se pode observar o sintoma e as causas históricas coexistente (UTÓPICO, 2019).

Segundo o PPP da escola, as hipóteses diagnosticadas pela Coordenação do AEE são levantadas de acordo com as observações feitas durante as entrevistas. Levando-se em conta as três linhas de pesquisa que serão realizadas: cognitiva, afetiva e orgânico funcional. Quando as hipóteses forem levadas a uma área específica (ex: psicologia, fonoaudiologia, neurologia etc.), a coordenadora do AEE solicita aos responsáveis uma avaliação de um profissional competente, sempre que possível. Após as sessões de diagnóstico do aluno é disponibilizado para a equipe escolar uma devolutiva a respeito do aluno, este documento é chamado de "consigna", que possibilita o conhecimento a cerca desse aluno referente às suas dificuldades, potencialidades, necessidades e intervenções necessárias para que este aluno possa desenvolver o seu processo de ensino aprendizagem permitindo um mapeamento e planejamento de ações e de atividades que poderão ser 
adotadas pelo docente no seu trabalho com este educando dentro da sala de aula juntamente com o professor de apoio e durante as sessões de atendimento no AEE.

Então, a Secretaria de educação especial do Ministério da educação disserta que

$\mathrm{O}$ atendimento educacional para tais alunos deve, portanto, privilegiar 0 desenvolvimento e a superação daquilo que the é limitado, exatamente como acontece com as demais deficiências, como exemplo: para o cego, a possibilidade de ler pelo Braille, para o surdo a forma mais conveniente de se comunicar e para a pessoa com deficiência física, o modo mais adequado de se orientar e se locomover (BRASIL, 2006, p. 18).

Outro apontamento importante do ministério da educação sobre 0 atendimento educacional especializado

não é ensino particular, nem reforço escolar. Ele pode ser realizado em grupos, porém atento para as formas específicas de cada aluno se relacionar com o saber. Isso também não implica em atender a esses alunos, formando grupos homogêneos com o mesmo tipo de problema (patologias) e/ou desenvolvimento. Pelo contrário, os grupos devem se constituir obrigatoriamente por alunos da mesma faixa etária e em vários níveis do processo de conhecimento. Alunos com síndrome de Down, por exemplo, poderão compartilhar esse atendimento com seus colegas autistas, com outras síndromes, sequelas de paralisia cerebral e ainda outros com ou sem uma causa orgânica esclarecida de sua deficiência e com diferentes possibilidades de acesso ao conhecimento (BRASIL, 2006, p. 19).

Nesta unidade de ensino os alunos que possuem laudo atestado por Médico Especialista em Neurologia ou Psiquiatria com Deficiência Intelectual ou Transtorno Global do Desenvolvimento são assistidos no $A E E$ e são acompanhados diariamente na sala de aula comum por professor de apoio que o auxilia em todas as atividades. Todas as atividades e avaliações são ofertadas de acordo com 0 artigo 59 da LDB, que garante a flexibilização curricular e adaptação das atividades e avaliações de acordo com as potencialidades de cada aluno, respeitando as suas limitações.

\section{DO DIREITO A EDUCAÇÃO ESPECIAL}

O direito à educação especial é constitucional (CF artigo 208), consta na Lei de Diretrizes e Bases do Ensino Nacional (LDB - Lei 9394/96), Estatuto da Criança e

RC: 98389

Disponível em: https://www.nucleodoconhecimento.com.br/educacao/trabalhopsicopedagogico 
do Adolescente ( Lei 853/89 ) e sustenta-se também na Declaração de Salamanca. De acordo com a Lei 9394/96, as escolas brasileiras devem desenvolver uma pedagogia de forma a contemplar todos os alunos. Os alunos com necessidades educacionais especiais devem receber todo apoio adicional necessário para garantir uma educação eficaz.

O Plano Nacional de Educação estabelece objetivos e metas para a educação das pessoas com necessidades educacionais especiais, essas metas tratam

- do desenvolvimento de programas educacionais em todos os municípios, e em parceria com as áreas de saúde e assistência social, visando à ampliação da oferta de atendimento da educação infantil;

- dos padrões mínimos de infraestrutura das escolas para atendimento de alunos com necessidades educacionais especiais;

- da formação inicial e continuada dos professores para atendimento às necessidades dos alunos;

- da disponibilização de recursos didáticos especializados de apoio à aprendizagem nas áreas visual e auditiva;

- da articulação das ações de educação especial com a política de educação para o trabalho;

- do incentivo à realização de estudos e pesquisas nas diversas áreas relacionadas com as necessidades educacionais dos alunos;

- do sistema de informações sobre a população a ser atendida pela educação especial (BRASIL, 2004).

A Lei $n^{\circ}$. 853/89. Dispõe sobre o apoio às pessoas com deficiências, sua integração social, assegurando o pleno exercício de seus direitos individuais e sociais. A Lei $n^{\circ}$. 8.069/90. Dispõe sobre o Estatuto da Criança e do Adolescente. O Estatuto da Criança e do Adolescente, entre outras determinações, estabelece, no inciso $1^{\circ}$ do 
Artigo $2^{\circ}$ que as crianças e adolescentes portadores de deficiências receberão atendimento especializado. Nenhum deles será objeto de qualquer forma de negligência, discriminação, violência, crueldade e opressão, punido na forma da lei qualquer atentado, por ação ou omissão, aos seus direitos fundamentais.

\section{LEI BRASILEIRA DE INCLUSÃO DA PESSOA COM DEFICIÊNCIA (ESTATUTO DA PESSOA COM DEFICIÊNCIA)}

A seguir será apresentada a Lei oㅜ 13.146, de 6 de julho de 2015, que destaca no primeiro artigo do Capítulo I a instituição da Lei Brasileira de Inclusão da Pessoa com Deficiência, conhecido como o Estatuto da pessoa com Deficiência. Esse estatuto tem como objetivo assegurar e promover igualdade no exercício dos direitos humanos e das liberdades fundamentais, tendo em vista a inclusão social e cidadania (BRASIL, 2015).

Já no artigo segundo, se determina quem são considerados pessoas com deficiência, consideradas então como àquelas que "tem impedimento de longo prazo de natureza física, mental, intelectual ou sensorial, o qual, em interação com uma ou mais barreiras, pode obstruir sua participação plena e efetiva na sociedade em igualdade de condições com as demais pessoas" (BRASIL, 2015).

No capítulo IV do estatuto da pessoa com deficiência, é descrito o direito à educação de tais indivíduos. Dessa forma, o Art. 27 da lei destaca que a educação é um direito da pessoa com deficiência, tendo assegurado educação inclusiva em todos os níveis de aprendizado ao longo da vida escolar, com o objetivo de desenvolver o máximo os talentos e habilidades da pessoa, seja elas físicas, sensoriais, intelectuais ou sociais. Além da escola, é dever do Estado, da família e da sociedade assegurar a educação de qualidade às pessoas com deficiência, deixando-as livre da violência, negligência e discriminação (BRASIL, 2015).

O art. 28, por sua vez "incumbe ao poder público assegurar, criar, desenvolver, implementar, incentivar, acompanhar e avaliar" tudo o que permeia os direitos da 
pessoa com deficiência, como o direito de ter o sistema educacional inclusivo em todos os níveis escolares e por toda a vida; aprimoramento do sistema educacional, garantindo acesso, permanência, participação e aprendizagem; projetos pedagógicos que institucionalizem o AEE, com objetivo de promover a autonomia de cada um; oferecer educação bilingue, ou seja, Libras como primeira língua, e a língua portuguesa como segunda; Desenvolver pesquisas que focam 0 desenvolvimento de "novos métodos e técnicas pedagógicas, de materiais didáticos, de equipamentos e de recursos de tecnologia assistiva; Adotar medidas que favoreçam o desenvolvimento linguístico, cultural, vocacional e profissional, despertando as habilidades e interesses do aluno com deficiência; Adotar práticas pedagógicas inclusivas em programas de formação inicial e continuada de professores; Formação de professores para AEE, além de tradutores e intérprete de Libras; Oferecer o ensino de Libras, Braille e utilização de tecnologia assistiva; Ter acesso a educação profissional, tecnológica e superior em igualdade aos demais; Garantir acesso às pessoas com deficiência a jogos e atividades recreativas, esportivas e de lazer no ambiente escolas, com igualdade aos demais; Acessibilidade; Oferta de profissionais de apoio escolar; e "articulação intersetorial na implementação de políticas públicas (BRASIL, 2015).

\section{RESULTADOS E DISCUSSÕES}

No início da pesquisa pode-se observar que a maioria dos professores ministravam suas aulas com metodologias tradicionais e que isso não estava sendo suficiente para atingir os alunos com maior dificuldade. Além das aulas tradicionais, a indisciplina das turmas também dificultava o aprendizado.

De acordo com a pesquisa realizada na sala do AEE os alunos são atendidos de acordo com as suas necessidades dando prioridade para os alunos com maior comprometimento de aprendizagem, eles são atendidos semanalmente, em grupos e/ou individualmente. No AEE são desenvolvidas as áreas da aprendizagem: comunicação e códigos, desenvolvimento cognitivo, tecnologia assistiva e enriquecimento curricular. Segundo os relatórios cedidos pela psicopedagoga dos 42 
alunos atendidos no AEE a maior dificuldade dos alunos está relacionada à concentração, atenção e memória comprometendo o aprendizado e acentuando dificuldades na leitura, na escrita, na interpretação, no raciocínio matemático e nas 4 operações matemáticas.

Numa pesquisa, Tessaro (2005) constatou que os conceitos dos participantes sobre inclusão escolar são insatisfatórios e que não houve diferenças entre os alunos e entre os professores quanto a essa dimensão. Os professores e os alunos expressaram várias dificuldades envolvidas nesse processo, como a falta de infraestrutura das escolas, a falta de capacitação profissional, discriminação social e a falta de aceitação da inclusão. Os participantes apontaram dificuldades no processo ensino-aprendizagem decorrentes da educação inclusiva.

Outros estudos também afirmam que a inclusão escolar vem se efetivando de forma inadequada e revelam o pouco interesse e investimento neste processo.

De acordo com os resultados apresentados nota-se que a maior limitação dos alunos está relacionada à dificuldade em concentração, isso sugere uma interferência muito grande na aprendizagem pois de acordo com estudos a falta de concentração compromete os estudos. E dentre as maiores potencialidades está o fato de os alunos dessa escola não apresentarem trocas de letras, tanto na fala como na escrita.

\section{CONSIDERAÇÕES FINAIS}

O presente estudo teve como objetivos analisar as práticas pedagógicas desenvolvidas no AEE (atendimento educacional especializado) para os alunos com necessidades educacionais especiais, conhecer as necessidades $e$ as potencialidades dos alunos com dificuldade escolar. Observou-se também que as práticas metodológicas desenvolvidas no AEE ressignifica e abrange uma perspectiva inclusiva. 
Assim, os processos de construção de práticas pedagógicas inclusivas precisam ter como parâmetros o objetivo de que a aprendizagem atinja todos os alunos para que as dificuldades sejam superadas para não para limitar as possibilidades de avanço, mas para evidenciar as conquistas.

Diante das constatações evidenciadas por ocasião da apreciação e da discussão dos resultados, acredita-se que se faz necessário o desenvolvimento de mais estudos que investiguem as causas das dificuldades de aprendizagem dos alunos em conjunto às diferentes práticas metodológicas, a fim de descobrir a influência desses tipos de metodologias realizadas no AEE desta unidade educacional para o desenvolvimento escolar dos alunos.

\section{REFERÊNCIAS}

ASBAHR, F. D. S. F. Por que aprender isso, professora? Sentido pessoal e atividade de estudo na Psicologia Histórico-Cultural. São Paulo, 2011.

BEYER, H. O. (2003). "A educação inclusiva: incompletudes escolares e perspectivas de ação." Revista Educação Especial 1(1): 33-44.

BRASIL. Constituição Federal. Constituição da República Federativa do Brasil. Brasília, DF: Centro Gráfico, 1988.

BRASIL. Lei no. 13.146, de 6 de julho de 2015. Institui a Lei Brasileira de Inclusão da Pessoa com Deficiência (Estatuto da Pessoa com Deficiência). Diário Oficial da União. Brasília, 2015.

BRASIL. Lei no 9.394, de 20 de dezembro de 1996. Estabelece as diretrizes e bases da educação nacional. Brasília, 1996.

BRASIL. Ministério da educação. Documento subsidiária à política de inclusão. Brasília, 2005.

BRASIL. Ministério da educação. Educação inclusiva. Brasília, 2006.

RC: 98389

Disponível em: https://www.nucleodoconhecimento.com.br/educacao/trabalhopsicopedagogico 
BRASIL. Ministério da educação. A fundamentação filosófica. Brasília, 2004.

CONSENZA, R. M.; GUERRA, L. B. Neurociências e Educação: como o cérebro aprende. Porto Alegre: Artmed, 2011.

FEDERAL, S. (2003). Constituição federal de 1988. Retrieved March,13, 2004.

FERNANDES, A. V. M.; PALUDETO, M. C. (2010). Educação e direitos humanos: desafios para a escola contemporânea. Cad. Cedes, 30(81), 233-249.

FERREIRA, M. E. C.; M. GUIMARÃES (2003). Educação inclusiva, DP \& A Rio de Janeiro.

GARCIA, Rosalba Maria Cardoso. Política de educação especial na perspectiva inclusiva e a formação docente no Brasil. Revista Brasileira de Educação, Florianópolis, v. 18, n. 52, p. 101-239, 2013.

GLAT, R. (2007). Educação Inclusiva: Cultura e Cotidiano Escolar, 7Letras.

GOOGLE. Desenvolvimento.

Disponível

em: https://www.google.com/search?q=dicion\%C3\%A1rio+online\&oq=dicion\%C3\%A1 rio +on\&aqs=chrome.0.0i433i512j69i57j0i512l2j0i433i512j0i512j46i512j0i512l3.3682j0j7 \&sourceid=chrome\&ie=UTF-8\#dobs=desenvolvimento. Acesso em: 30 jul. 2021.

HOUAISS, A. (2002). Dicionário inglês-português, Record.

KUNC, Thomas S. A estrutura das revoluções científicas. São Paulo, Editora Perspectiva, 1992.

LEÃO, A. M. D. C.; GARCIA, C. A. A.; YOSHIURA, E. V. F.; RIBEIRO, P. R. M. (2006). Inclusão do aluno com dismotria cerebral ontogenética: análise das práticas pedagógicas. Revista Brasileira de Educação Especial, 169-186. 
MANTOAN, M. T. E. (2003). Inclusão Escolar: o que é? por quê? como fazer?, Summus Editorial.

MANTOAN, M. T. E.; PRIETO R. G.; ARANTES, V. A. (2006). Inclusão escolar: pontos e contrapontos, creaphis editions.

MESERLIAN, Kátia Tavares. Análise do processo de inclusão de alunos surdos em uma escola municipal de Arapongas. Londrina: UEL, 2009. (Dissertação de mestrado)

MIOTTO, Ana Cristina Felipe. A prática curricular e suas implicações no trabalho com os educandos com deficiência visual: avanços e impasses na inclusão. Minas Gerais: PUC, 2010. (Dissertação de mestrado)

OLIVEIRA, R. P. d. (1999). O Direito à Educação na Constituição Federal de 1988 e seu restabelecimento pelo sistema de Justiça. Revista Brasileira de Educação 11: $61-74$

PENTEADO, T. C. Z.; GUZZO, R. S. L. (2010). Educação e psicologia: a construção de um projeto político-pedagógico emancipador. Psicologia e Sociedade, 22(3), 569-577.

PIVETA, Mara K.; RODRIGUES, Marisa M. F.; NOGUEIRA, S. R. B. Inclusão: jogar nesse time nos leva à vitória. In: ROTH, Berenice W. (org.). Experiências educacionais inclusivas: Programa Educação Inclusiva: direito à diversidade. Brasília: Ministério da Educação, Secretaria de Educação Especial, 2006.

ROSAT, Renata Menezes et al. Emergência da Neuro educação: a hora e a vez da neurociência para agregar valor à pesquisa educacional. Ciências e Cognição, v. 15, n. 1, p. pp. 199-210, 2010.

SARTORETTO, M. L. (2009). Inclusão: da concepção à ação. O desafio das diferenças nas escolas 2 .

RC: 98389

Disponível em: https://www.nucleodoconhecimento.com.br/educacao/trabalhopsicopedagogico 
STRECK, D. Correntes pedagógicas: aproximações com a teologia. Petrópolis: Vozes, 1994.

TESSARO, N. S. (2005). Inclusão escolar: concepções de professores e alunos da educação regular e especial. Casa do Psicólogo.

UNESCO. Educação inclusiva no Brasil. Disponível em: https://pt.unesco.org/fieldoffice/brasilia/inclusive-education. Acesso em: 30 jul. 2021.

UTÓPICO, João Maria Andarilho. EOCA: Entrevista Operativa Centrada na Aprendizagem. $2019 . \quad$ Disponível em: https://educacaodialogica.blogspot.com/2019/07/eoca-entrevista-operativa-centradana.html. Acesso em: 30 jul. 2021.

VISCA, J. (1995). El diagnóstico operativo en la práctica psicopedagógica. Palabra gráfica y Editora SA Capital Federal.

VYGOTSKY, L. V. (1991). A formação social da mente: desenvolvimento dos processos mentais superiores. Livraria Martins Fontes Editora Ltda. São Paulo - SP $19914^{a}$ edição brasileira.

Enviado: Junho, 2021.

Aprovado: Outubro, 2021.

RC: 98389

Disponível em: https://www.nucleodoconhecimento.com.br/educacao/trabalhopsicopedagogico 